Journal of Advanced Research in Fluid Mechanics and Thermal Sciences

Journal homepage: www.akademiabaru.com/arfmts.html ISSN: 2289-7879

\title{
Evaluation Of Cutting Force in End Milling Process of Aluminum Alloy 6061-T6 Using Tungsten Carbide Inserts with MQL Method Utilizing Hybrid Nanofluid
}

\author{
Wahaizad Safiei ${ }^{1,}{ }^{*}$, Md Mustafizur Rahman ${ }^{2}$, Ahmad Razlan Yusoff ${ }^{3}$, Wajiha Tasnim ${ }^{3}$, Zetty Akhtar \\ Abd Malek ${ }^{3}$
}

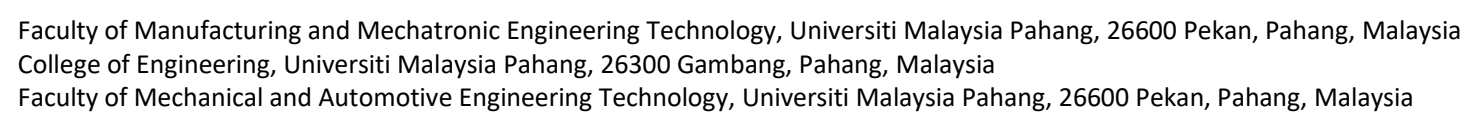

\section{ARTICLE INFO}

Article history:

Received 26 December 2020

Received in revised form 27 May 2021

Accepted 3 June 2021

Available online 2 July 2021

Keywords:

End milling process; Tri-hybrid nanofluids; cutting force; MQL

\section{ABSTRACT}

\footnotetext{
* Corresponding author.

E-mail address: wahaizad.safiei@gmail.com
}

https://doi.org/10.37934/arfmts.84.1.111125

\begin{abstract}
As an alternative to conventional metal working fluid in the end milling process, a combination of newly developed tri-hybrid $\mathrm{SiO}_{2}-\mathrm{Al}_{2} \mathrm{O}_{3}-\mathrm{ZrO}_{2}$ in aqueous-based nanofluid was delivered to the cutting zone using the MQL technique. The liquid has excellent thermal-rheology properties that can offer effective cooling and lubricating during the process. The tri-hybrid nanofluid application is environmentally safe, thus promoting sustainable manufacturing compared to the conventional working fluid. In this experimental study, the cutting forces were investigated comprehensively. Tri-hybrid nanofluid presents in atomizing conditions using the minimum quantity lubricant (MQL) technique at the cutting zone. Industrial standard inserts, namely uncoated, CVD TiCN-Al ${ }_{2} \mathrm{O}_{3}$ and PVD TiAITaN tungsten carbide used in the experiments. End milling process variables were cutting speed, feed rate, depth of cut, MQL flow rate and nanofluid concentrations. The response data were analyzed statistically based on the design of experiment and regression models were developed for each response according to response surface methodology. Higher cutting force was observed at extreme machining parameters, which regards to higher material removal rate. During the cutting process of Aluminum Alloy 6061-T6, the cutting force, Fr measured was between 16 Newton and 30 Newton. The cutting force in $\mathrm{Y}$-axes (Fy) demonstrates a higher magnitude than others due to the cutting feed of AA6061-T6 in the $\mathrm{Y}$ direction. CVD TiCN-Al $\mathrm{O}_{3}$ tungsten carbide exhibited higher cutting force (Fy) due to coated hardness and tool failures mechanism on both rake and flank face as the wear phenomenon will increase the land contact area. In summary, the resultant cutting force (Fr) was recorded below 30 Newton, indicating the significant improvement in the end milling process. For future experimental works, the cutting force can be explored by considering different nanofluids, extreme machining conditions and brittle material.
\end{abstract}




\section{Introduction}

In the metal cutting process, lubrication is an important aspect that has remarkable effects on machining performance. Applying lubricants during the cutting process can reduce cutting temperature and mechanical forces to enhance the process performance. Metal working fluid has significantly influenced the material plastic deformation and the cooling rate, particularly for both workpiece and tool [1]. However, in one aspect, conventional metal working fluid negatively affects the environment, health and safety. Besides, a higher consumption rate of fluid and energy reflecting higher manufacturing costs. Therefore, nanofluids capabilities have been explored extensively as a metal working fluid replacement for the future. Nanofluids have manifested and promising in machining, which regards thermal-rheology behavior to provide adequate heat transfer and tribology characteristics at the cutting interface. According to Xiufang et al., [2], the $\mathrm{Al}_{2} \mathrm{O}_{3}$ and $\mathrm{SiO}_{2}$ nanoparticles in cottonseed oil demonstrated excellent lubrication performance in surface roughness and milling forces compared to other nanoparticles when removing titanium alloy Ti-6Al-4V. During the cutting process, nanoparticles behave as rolling bearings, protective layers and producing mending effects that reduce friction during machining.

The large quantity of conventional metal-cutting fluid can expose harmful chemical elements for long hours, resulting in skin and lung disease. Besides, the flooded lubrication technique requires more working fluid. An additional cost is needed to treat the fluid with biocide for reuse purposes, which led to a higher manufacturing cost [3]. In order to reduce the metal working fluid consumption in the process, a combination of the MQL technique that is utilizing nanofluids can be explored. MQL was introduced by Kibira et al., in 2010 [4], receives wider attention as this technique can improve lubricating and machining performance. Besides, it is a greener approach to manufacturing sustainability. Therefore, the application of MQL in metal-cutting processes offers a harmless environment for the workers, subsequently reducing health risk-related issues. In the MQL technique, a part of the atomization of lubrication fluid at the cutting zone can penetrate the cutting interface. Simultaneously, high-pressure air plays an essential role in cooling and removing debris [5].

Driven by green technology in this era and promoting sustainable manufacturing, nanofluids are introduced as an alternative to the conventional working fluid. Nanofluids are engineered colloidal suspension in a base fluid for minimizing environmental effects and enhancing working fluid thermal and rheology properties. The innovative approach of a newly developed working fluid, especially for the application, requires the fluid's excellent thermal and tribology characteristics. Aluminum Alloy 6061-T6 tends to adhere to higher cutting temperatures, causing the tool to wear failures. As a result, it may affect the cutting force and shorten the tool life. Regarding the economic aspect, especially in mass production [6,7], AA6061-T6 is the most suitable choice as a raw material for producing custommade and complex shape engineering products. Due to its light-weight and easy for fabrication, AA6061-T6 was preferred material in aerospace applications [8].

In the end milling process, it is essential to control the amount magnitude of the cutting force that would acquire the end milling process's efficiency. The friction forces at the cutting tool and workpiece interface have a significant effect on tool wear and tool life. In addition, the machining performances such as dimensional accuracy, tool wear, cutting temperature and forced vibration have a strong correlation to cutting force [9]. Cutting forces are essential variables in the cutting process that reflecting the severity of tool wear. The friction forces in the direction of cutting velocity act as energy for shearing and deforming the material. Cutting forces can be defined as the required forces to remove the material which acts in the direction of tool feed either in $\mathrm{x}, \mathrm{y}$ or $\mathrm{z}$-axes and supplies a collective amount of energy to perform the cutting process [10]. A relative motion between the cutting tool and the material is required before producing the cutting force. During the cutting 
process, cutting forces present naturally with tool geometry and machining parameters such as cutting speed and feed rate.

The characteristics of cutting with a different tool can be identified and analyzed by collecting data of cutting force. For this reason, to explore the relationship between cutting forces and tool wear propagation in improving the process is always recognized as a challenging problem [11]. Moreover, controlling and monitoring both cutting forces and tool wear and changing the tool is another issue that must be addressed to ensure timely replacement, resulting in an excellent quality of machining accuracy [12]. Sultan and Okafor, (2016) reported that the cutting force component in the feed direction (Fy) was the largest in magnitude, followed by the force perpendicular to the feed direction (Fx) and the axial cutting force (Fz) [13]. It found that by increasing the helix angle $(\gamma)$ of tool geometry from $25^{\circ}$ to $30^{\circ}$, Fy and Fx's cutting forces significantly reduced. Selvaraj revealed that the feed rate was the most significant factor at $46 \%$ influencing the cutting force and the optimum value for feed rate was $63 \mathrm{~mm} / \mathrm{min}$ in minimizing the cutting force [14]. Oganyan et al., [15] revealed that coating adhesive bonding plays an important role in reducing Titanium Alloy's cutting force as coating delamination generated fluctuation values of forces that represent minor vibration during the cutting process.

The application of tri-hybrid nanofluids with the MQL method in the end milling process in reducing the cutting forces has not been reported in the literature. Therefore, this is an attempt to discover the potential of a new generation of metal working fluid in the metal cutting process's high speed utilizing tri-hybrid nanoparticles. This study's main objective is to evaluate end milling performance using industrial standard inserts in terms of cutting force by applying the MQL method and $\mathrm{SiO}_{2}-\mathrm{Al}_{2} \mathrm{O}_{3}-\mathrm{ZrO}_{2}$ tri-hybrid aqueous-based nanofluid. The study can be considered a novel contribution, employing tri-hybrid nanofluid, MQL and high cutting speed to remove AA6061-T6. The analysis of the cutting forces was based on different inserts according to the experiment's design and response surface methodology. The correlations between significant factors were represented in mathematical modeling and graphical plots.

\section{Methodology}

In this investigation study, a newly developed tri-hybrid $\mathrm{SiO}_{2}-\mathrm{Al}_{2} \mathrm{O}_{3}-\mathrm{ZrO}_{2}$ in aqueous-based nanofluids was delivered in the cutting zone using the MQL technique. Three different nanoparticles were dispersed into a 60:40 mixing ratio of ethylene glycol and deionized water. Upon preparation, the samples seem stable as the nanoparticles were well dispersed in the suspension. Tri-hybrid $\mathrm{SiO}_{2-}$ $\mathrm{Al}_{2} \mathrm{O}_{3}-\mathrm{ZrO}_{2}$ nanofluids offer excellent thermal-rheology properties that can effectively dissipate the heat and reduce friction forces. Aluminium Alloy $6061-T 6$ with a $100 \mathrm{~mm} \times 100 \mathrm{~mm} \times 30 \mathrm{~mm}$ dimension was used as a workpiece in the experiments. The blocks have four counter-bores at the center of the workpiece with a $15 \mathrm{~mm}$ diameter to allow tight, neat and robust mounting of the workpiece on the Neo-Momac dynamometer. Hence, high reliable data can be collected. The uneven distribution of forces can be avoided when the workpiece has no weakness point occurred along the cutting process that may affect data accuracy. Experiments were conducted based on the design of experiment method with five input parameters. The experimental design plan consists of 32 experiments for a single type of insert. It is five factors and five-level central composite rotatable designs consisting of 32 sets of coded conditions. The experiment's design comprises a $1 / 2$ replication of 25 , which equivalent to 16 of factorial design with additional six center points and ten-star points. These correspond to the first 16 rows of factorial design, the last six rows of center points and rows from 17 to 26 of star points, respectively, with the actual value of machining parameters as shown in Table 1. 


\section{Table 1}

Experimental planning based on single composition ratio of three different nanoparticles for End Milling Parameters of Aluminium Alloy 6061-T6

\begin{tabular}{llllll}
\hline Input Cutting Parameter & \multicolumn{3}{l}{ Level of input cutting parameter } & & Highest \\
\cline { 2 - 6 } & Lowest & Low & Centre & High & \multicolumn{1}{l}{$\begin{array}{l}\text { Highe } \\
(+\alpha)\end{array}$} \\
\hline Cutting speed (rpm) & $(-\alpha)$ & $(-1)$ & $(0)$ & 1100 & 12000 \\
Feed rate (mm/min) & 8000 & 9000 & 1000 & 100 & 250 \\
Depth of cut (mm) & 50 & 100 & 150 & 200 & 1.5 \\
MQL Flow Rate (mL / min) & 0.5 & 0.75 & 1.0 & 1.25 & 1.8 \\
Nanoparticle weight concentration (\%) & 0.6 & 0.9 & 1.2 & 1.5 & 0.12 \\
\hline
\end{tabular}

In every run of the experiment, a new cutting insert is used to remove $100 \mathrm{~mm}$ through slots to obtain consistent and reliable results, as recommended by Abdullah et al., [16]. Three different inserts, namely uncoated, CVD TiCN-Al ${ }_{2} \mathrm{O}_{3}$ and PVD TiAlTaN tungsten carbide, were used in the experiments. Figure 1 shows three inserts with code numbers and dimensions in millimeters that adhere to cutting inserts' industrial standards. The most common method to measure cutting forces in the end milling process is through a table Dynamometer. This metrology has piezoelectric sensors that are clamped between two plates [17]. The dynamometer is connected with data acquisition to amplify and convert the signal so that the cutting force data can be stored, displayed and analyzed. In this study, a set of table dynamometer, data acquisition system (DAQ) and software brand NeoMomac made by Universiti Kebangsaan Malaysia system was used as shown in Figure 2. Dynamometers or force transducers can be employed to measure the cutting force in the $\mathrm{x}, \mathrm{y}$ and $\mathrm{z}$ axes. Hence, cutting force can be computed, as shown below [18] in Eq. (1).

Cutting Force, $F_{c}=\sqrt{\left(F_{x}^{2}\right)+\left(\mathrm{F}_{y}^{2}\right)+\left(\mathrm{F}_{z}^{2}\right)}$

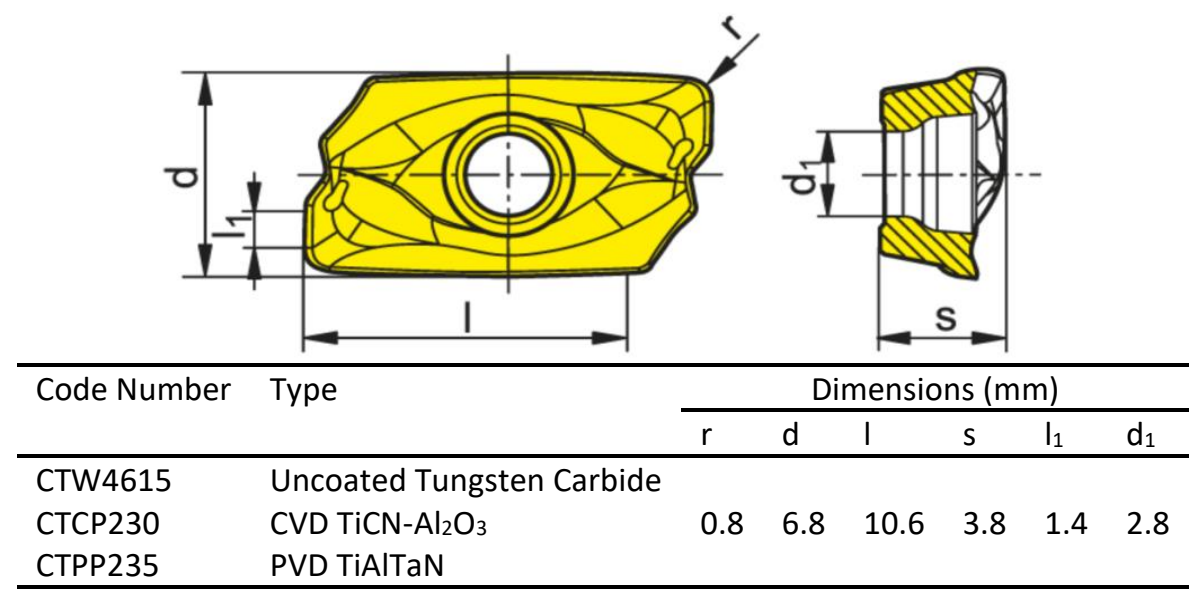

Fig. 1. Dimensions of CTW4615, CTCP230 and CTPP235 inserts. (Source: CERATIZIT CO) 


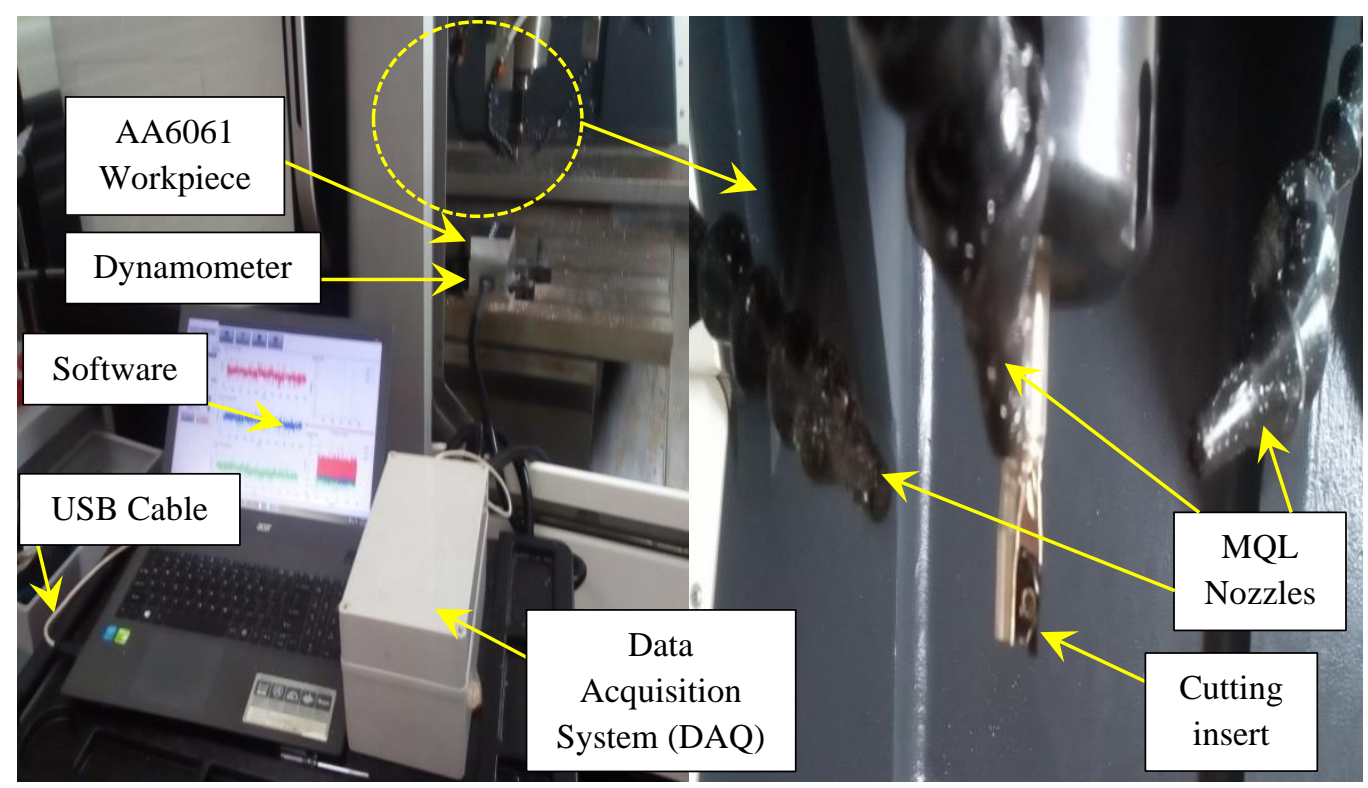

(a)

(b)

Fig. 2. Experimental setup consists of (a) Dynamometer (strain-gauge based) and Data acquisition system (DAQ) model Neo-Momac manufactured by UKM and (b) MQL nozzle formation

\section{Results}

In this section, the effect of $\mathrm{SiO}_{2}-\mathrm{Al}_{2} \mathrm{O}_{3}-\mathrm{ZrO}_{2}$ tri-hybrid nanofluids on cutting force at the end milling process using uncoated, CVD TiCN-Al ${ }_{2} \mathrm{O}_{3}$ and PVD TiAITaN tungsten carbide to be presented. Actual experimental data of cutting force in the machining of Aluminum Alloy 6061-T6 are analyzed based on analysis of variance, central composite rotatable design and response surface methodology. The cutting forces were recorded in X-axes, $Y$-axes and Z-axes during machining of Aluminum Alloy 6061-T6 using a dynamometer for each run. However, based on different forces, cutting force, Fr is computed and applied in the experiment table design for further analysis. Table 2 summarizes the ANOVA table for cutting force (CF) of uncoated, CVD TiCN-Al $\mathrm{O}_{3}$ and PVD TiAITaN tungsten carbide for response surface linear model in end milling of AA6061-T6. In the ANOVA table, the significant effects are indicated by the value of "Prob>F," which less than 0.05. It is found that Cutting Speed $(A)$, Feed Rate (B), Depth of Cut (C), MQL Flow Rate (D), Concentration (E), AC, AE, BC, BD, BE and CD are significant factors for uncoated tungsten carbide influencing the cutting force of Aluminum Alloy 6061-T6. Meanwhile, for cutting force of CVD TiCN-Al ${ }_{2} \mathrm{O}_{3}$ tungsten carbide, it is shown that Cutting Speed (A), Feed Rate (B), Depth of Cut (C), MQL Flow Rate (D), Concentration (E), AB and C2 are significant factors for cutting force. Similar results reveal that Cutting Speed (A), Feed Rate (B), Depth of Cut (C), MQL Flow Rate (D), Concentration (E), $A B, A C$ and $A D$ are significant factors for PVD TiAITaN. Hence, from the Box-Cox plot, it was found that there was no transformation required of cutting force for all types of inserts used.

The two-factor interactions have behaved in linear regression for both uncoated and PVD TiAITaN tungsten carbide. However, polynomial regression is required in developing the model for CVD TiCN$\mathrm{Al}_{2} \mathrm{O}_{3}$ tungsten carbide. Other insignificant factors and interactions have been removed from the ANOVA table during model selection. These terms can be ignored except those terms required to support hierarchy and might improve the model. The backward elimination step is applied to reduce the model terms, which are not significant. It is vital to ensure the model is fit for the analysis. The models are valid and fit due to lack of fit is greater than 0.05 , resulting in not significant, which is desirable for the analysis and the R-Squared value is close to 1 . The Predicted $R^{2}$ is in reasonable 
agreement with the Adjusted $\mathrm{R}^{2}$, in which the difference is less than 0.2 . Adeq precision measures the noise ratio signal, which a ratio greater than 4 is desirable in the analysis. Hence, the models obtained for the cutting force can be used to navigate the design space. Overall, the analysis and the models developed of cutting force for Aluminum Alloy 6061-T6 using uncoated, CVD TiCN-Al ${ }_{2} \mathrm{O}_{3}$ and PVD TiAITaN and tungsten carbide are statistically valid and fit.

\section{Table 2}

ANOVA table for cutting force of uncoated, CVD TiCN-Al $\mathrm{O}_{3}$ and PVD TiAITaN tungsten carbide in end milling of Aluminum Alloy 6061-T6

\begin{tabular}{lllll}
\hline Source & Uncoated & $\mathrm{CVD} \mathrm{TiCN}_{\mathrm{Al}} \mathrm{O}_{3}$ & $\mathrm{PVD}$ TiAlTaN & Remarks \\
\hline Model & significant & significant & significant & $\mathrm{p}$-value $<0.0001$ \\
Significant factors & $\mathrm{A}, \mathrm{B}, \mathrm{C}, \mathrm{D}, \mathrm{E}, \mathrm{AC}, \mathrm{AE}, \mathrm{BC}, \mathrm{BD}, \mathrm{BE}, \mathrm{CD}$ & $\mathrm{A}, \mathrm{B}, \mathrm{C}, \mathrm{D}, \mathrm{E}, \mathrm{AB}, \mathrm{C}^{2}$ & $\mathrm{~A}, \mathrm{~B}, \mathrm{C}, \mathrm{D}, \mathrm{E}, \mathrm{AB}, \mathrm{AC}, \mathrm{AD}$ & $\mathrm{p}$-value<0.05 \\
Lack of fit & 0.7173 & 0.3802 & 0.1050 & Not significant \\
$\mathrm{R}^{2}$ & 0.8382 & 0.6494 & 0.7374 & Close to 1 \\
Adeq precision & 12.3154 & 10.9685 & 11.8573 & Greater than 4 \\
\hline
\end{tabular}

Figure 3 shows the plot of residuals for cutting force for three cutting inserts scattered on a straight line on the normal probability plot indicating that the errors are distributed normally.

Based on the analysis of variance, the regression models of the cutting force of Aluminum Alloy 6061-T6 in terms of actual value are derived by the design expert software to make predictions for the response parameter for each factor and interactions. Eq. (2), (3) and (4) are mathematical modeling of cutting force actual factors for all types of inserts used in the experiments. The regression models are also useful for identifying the optimum condition and relative impact of the factors by comparing the factor coefficients. The final equation in terms of actual factors for cutting force

$$
\begin{aligned}
& Y_{\text {uncoated }}=-14.8027+0.00471438 x_{1}+0.0396875 x_{2}-61.3893 x_{3}-19.7639 x_{4} \\
& +844.813 x_{5}+0.0042575 x_{1} x_{3}-0.0699375 x_{1} x_{5}+0.04955 x_{2} x_{3}+0.063875 x_{2} x_{4} \\
& -1.43375 x_{2} x_{5}+11.5417 x_{3} x_{4} \\
& Y_{C V D}=24.8561+0.00100292 x_{1}-0.0260292 x_{2}+13.8315 x_{3}-3.27361 x_{4}-104.958 x_{5} \\
& +0.06465 x_{2} x_{3}-13.1427 x_{3}^{2} \\
& Y_{P V D}=141.842-0.0105571 x_{1}-0.19125 x_{2}+40.16 x_{3}-50.9333 x_{4}-109.5 x_{5} \\
& +2.105 e^{-5} x_{1} x_{2}+0.004385 x_{1} x_{3}+0.004525 x_{1} x_{4}
\end{aligned}
$$

where, $x_{1}$ is cutting speed $(\mathrm{rpm}), \mathrm{x}_{2}$ is feed rate $(\mathrm{mm} / \mathrm{min}), \mathrm{x}_{3}$ is depth of cut $(\mathrm{mm}), \mathrm{x}_{4}$ is MQL flow rate $(\mathrm{mL} / \mathrm{min})$ and $x_{5}$ is concentration (wt.\%).

Similar trends of all five single factors affecting cutting force were observed in this section. All five single machining factors behave in the same way with the previous responses influenced the response parameters. Both regression models and one-factor interaction show that a low level of cutting speed (A), feed rate (B) and depth of cut (C) have a remarkable effect in obtaining a lower cutting force of AA6061-T6. On the other hand, a high level of MQL flow rate and Concentration reflecting the outstanding cutting force of Aluminum Alloy 6061-T6 in the end milling process irrespective of cutting inserts. 


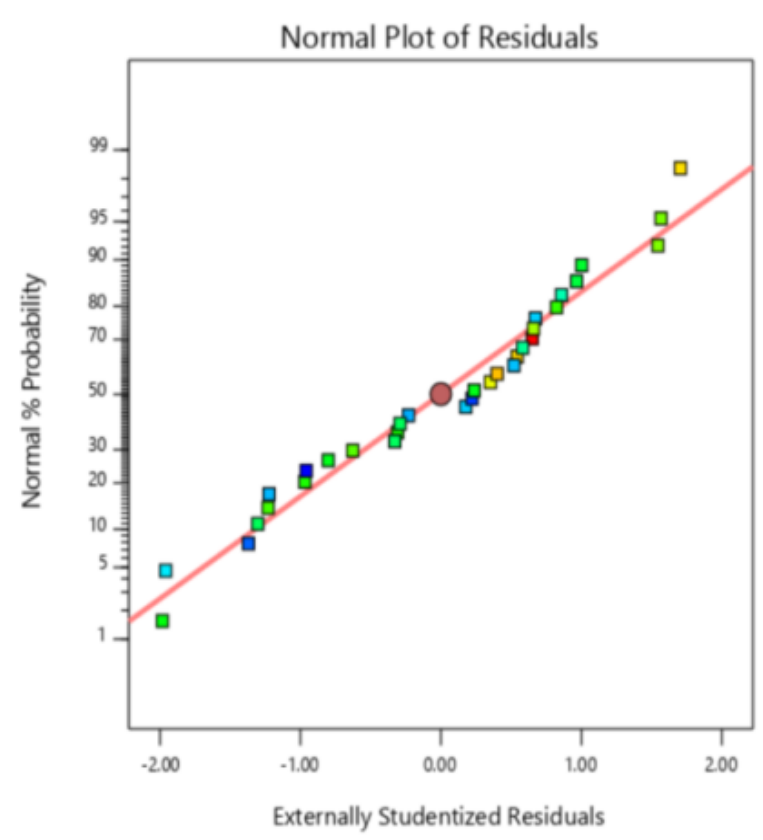

(a)

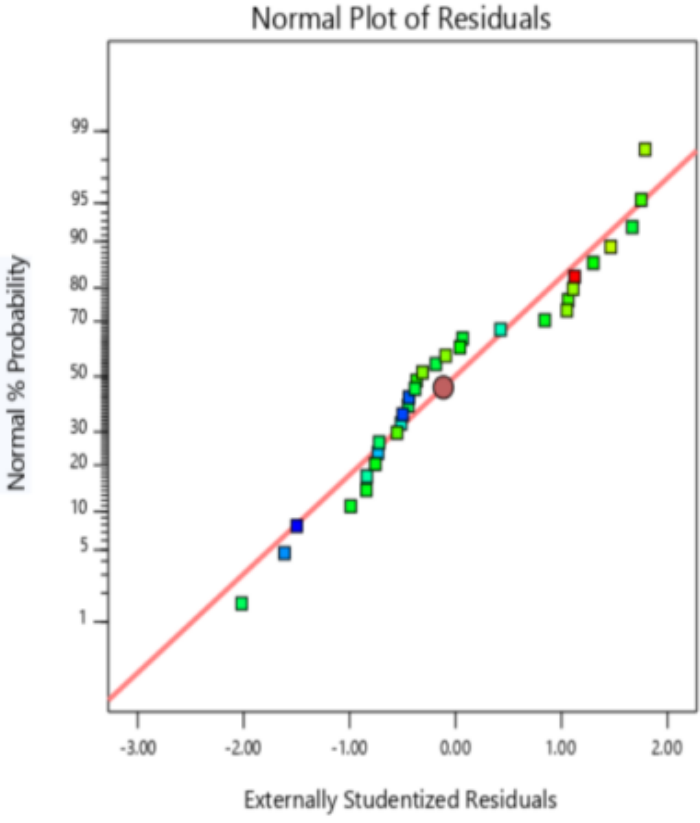

(b)

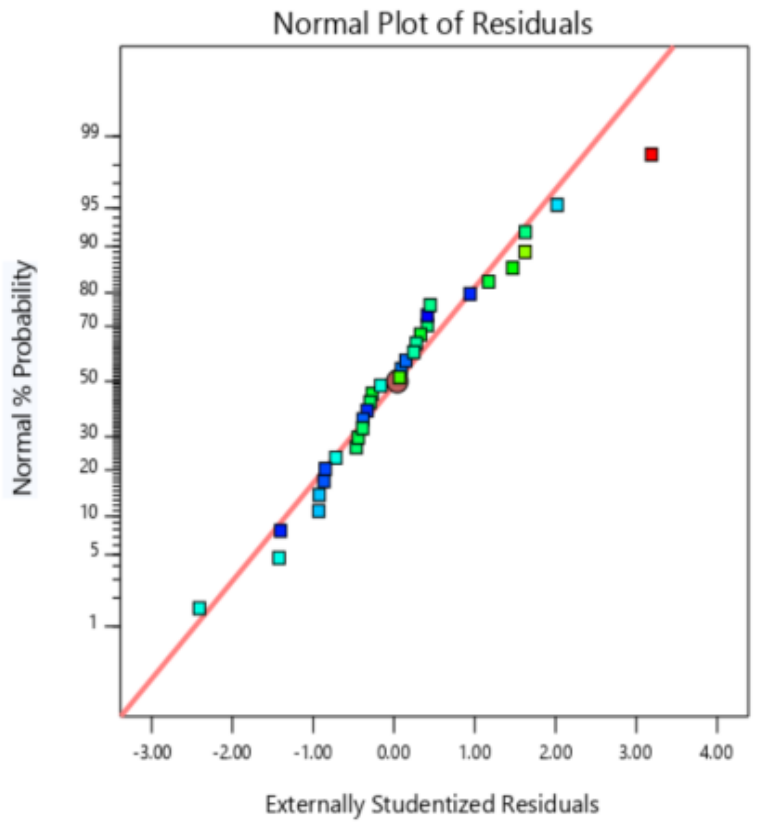

(c)

Fig. 3. Normal probability plot for cutting force for (a) uncoated tungsten carbide, (b) $\mathrm{CVD}$ TiCN- $-\mathrm{Al}_{2} \mathrm{O}_{3}$ and (c) PVD TiAITaN

In this section, the cutting force response shows in a 3D surface graphical plot with different interactions generated by the design expert version 9 software. The analysis shows six interactions involving two different factors that are significant for the cutting force of Aluminum Alloy 6061-T6 using an uncoated tungsten carbide insert. Figure 4 shows two factors interaction between significant effects, namely (a) cutting speed (A) and depth of cut (C), (b) cutting speed (A) and concentration (E), (c) feed rate (B) and depth of cut (C), (d) feed rate (B) and MQL flow rate (D), (e) feed rate (B) and concentration (E) and ( $f$ ) depth of cut (C) and MQL flow rate (D) influencing cutting force. Similar results were obtained for CVD TiCN-Al $\mathrm{O}_{3}$ and PVD TiAITaN tungsten carbide, which the two-factor interactions as shown in Figure 5 and 6, respectively. Both graphs behave on a linear surface, displaying the minimum cutting force at the lowest surface of the graph. However, the two-factor 
interactions of CVD TiCN-Al $\mathrm{O}_{3}$ tungsten carbide involving feed rate (B) and depth of cut (C) and cutting speed (A) and depth of cut (C) behave in curvature surface for the response studied as shown in Figure 5.

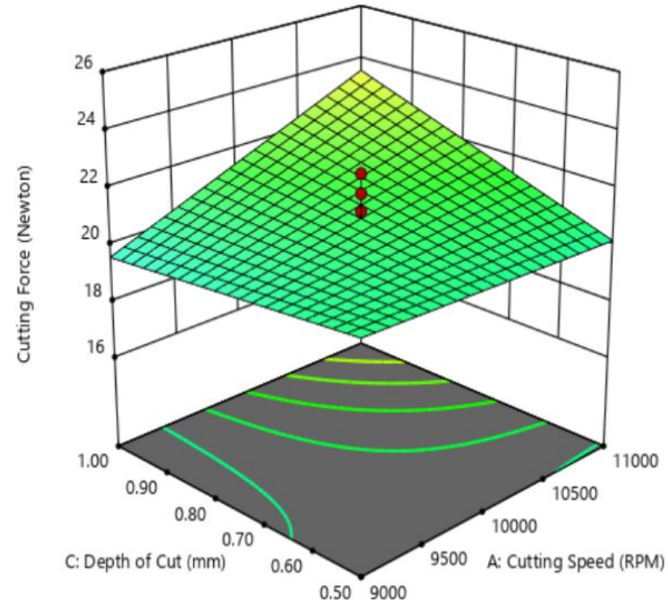

(a)

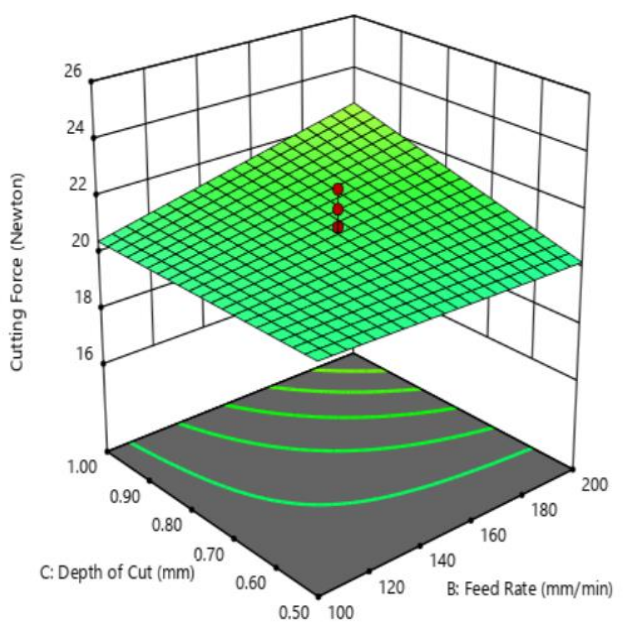

(c)

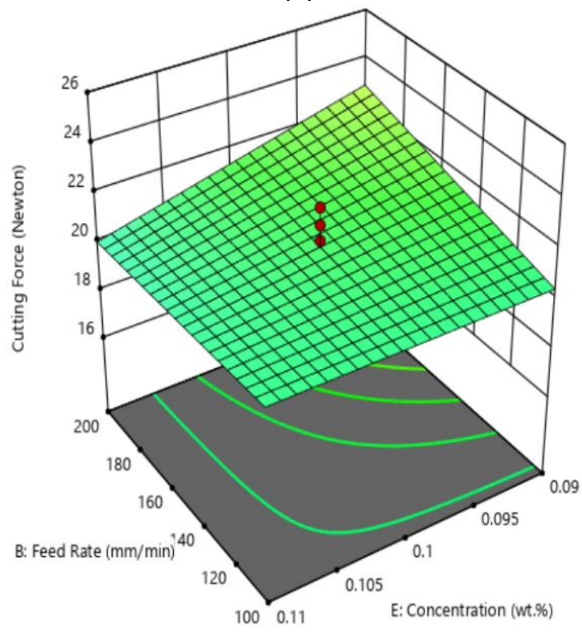

(e)

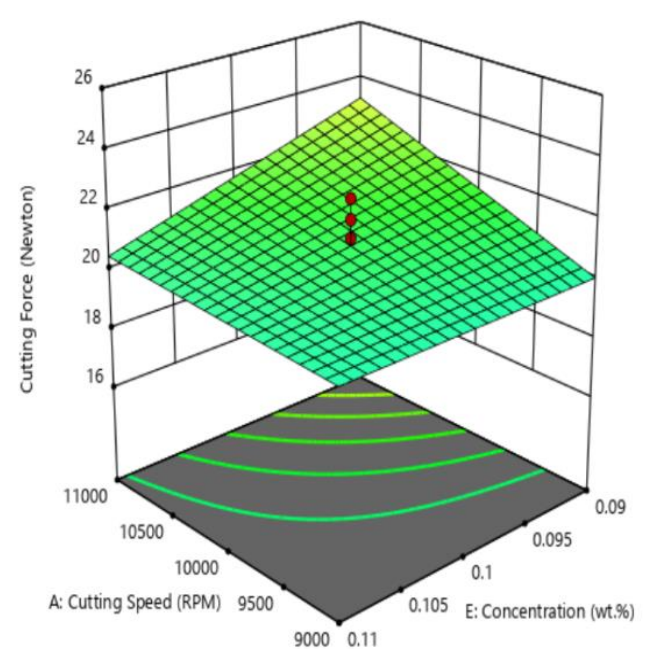

(b)

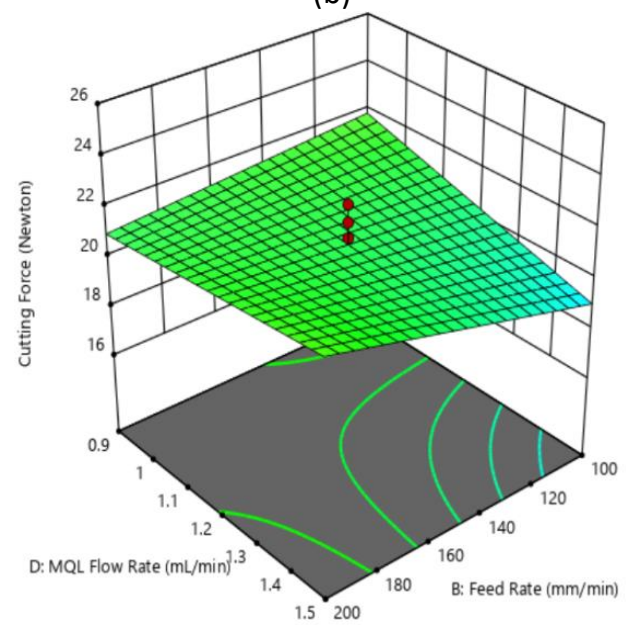

(d)

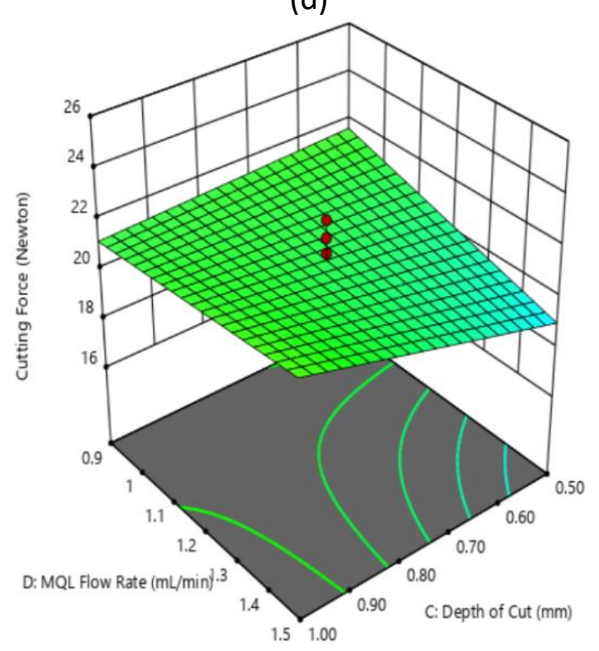

(f)

Fig. 4. $3 D$ graphical plots of cutting force using uncoated tungsten carbide between two-factor interaction (a) cutting speed and depth of cut, (b) cutting speed and concentration, (c) feed rate and depth of cut, (d) feed rate and MQL flow rate, $(e)$ feed rate and concentration and $(f)$ depth of cut and MQL flow rate 


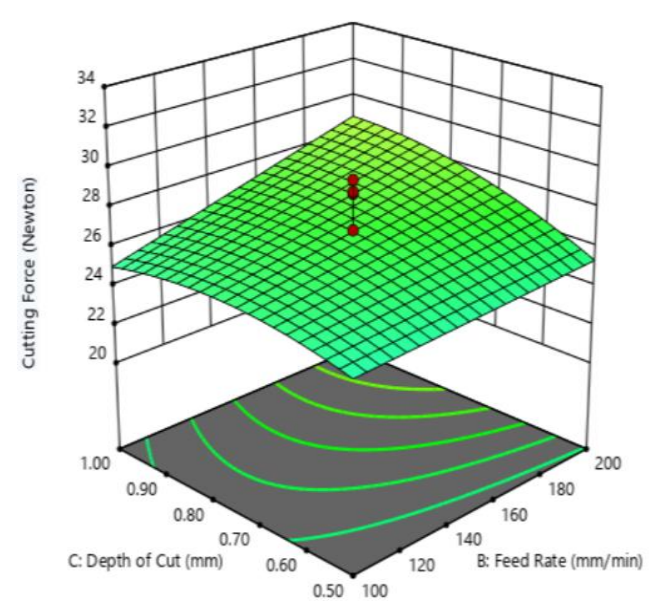

(a)

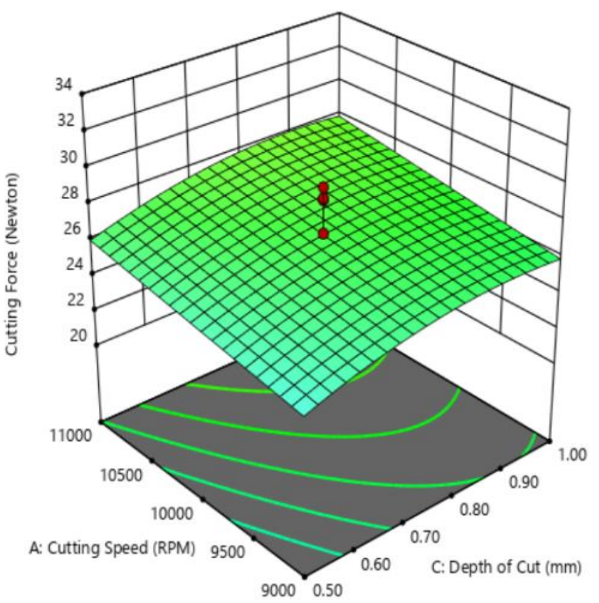

(b)

Fig. 5. 3D graphical plots of cutting force using $\mathrm{CVD}$ TiCN-Al${ }_{2} \mathrm{O}_{3}$ tungsten carbide between two-factor interaction (a) Feed rate and depth of cut and (b) Speed and depth of cut

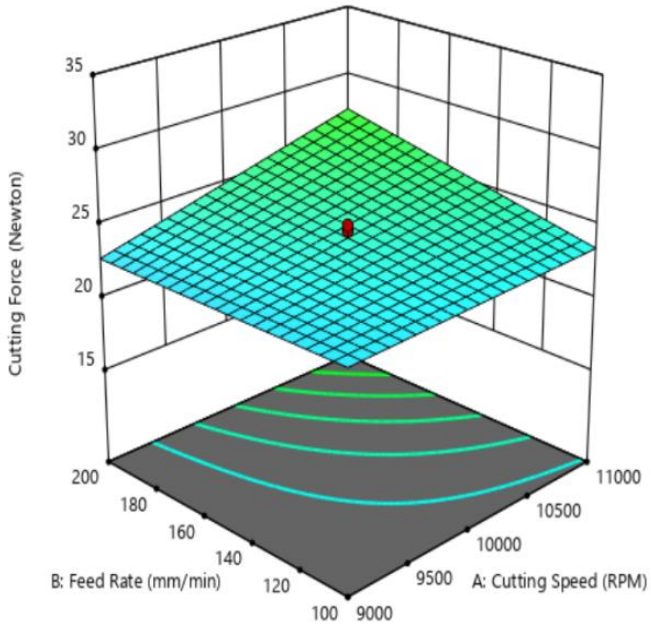

(a)

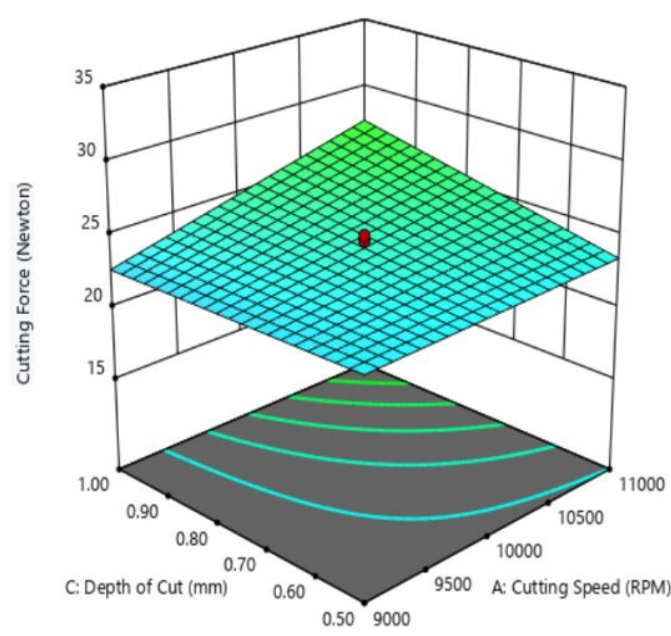

(b)

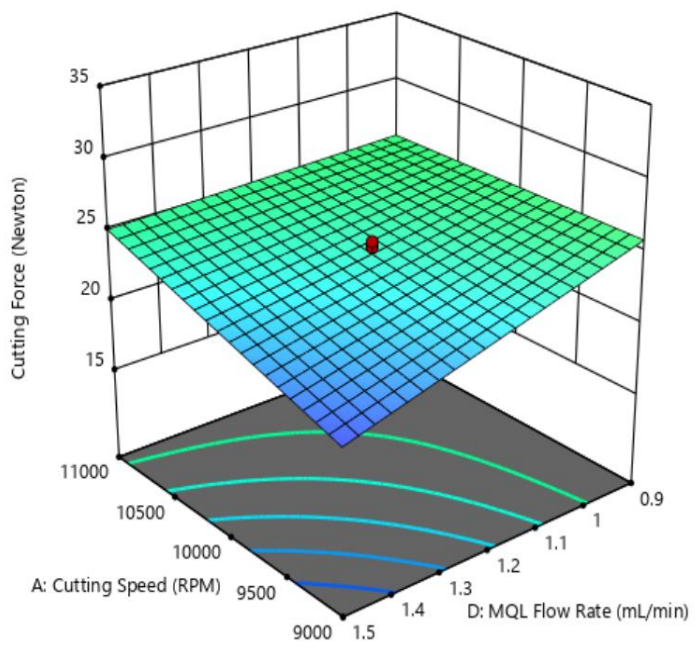

(c)

Fig. 6. 3D graphical plots of cutting temperature using PVD TiAlTaN tungsten carbide between two-factor interaction (a) cutting speed and feed rate, (b) cutting speed and depth of cut and (c) cutting speed and MQL flow rate 
Cutting force increased when the material was removed at a higher removal rate with the cutting process's rapid feeding. Nevertheless, during the cutting process of Aluminum Alloy 6061-T6, the cutting force, Fr measured was between 16 Newton and 30 Newton. The measurement value can be considered low in the machining of Aluminum Alloy 6061-T6. These are outstanding results, particularly in applying $\mathrm{SiO}_{2}-\mathrm{Al}_{2} \mathrm{O}_{3}-\mathrm{ZrO}_{2}$ tri-hybrid nanofluids at the cutting zone. The presence of nanofluids in higher concentration and volume may help form a thin film on the machined surface, thus producing a significant reduction of cutting force.

A dynamometer generated the raw data of the cutting force during the machining process. The data have to be appropriately selected in the $x, y$ and $z$ axes, particularly during the cutting process. The analysis of cutting force was conducted according to the analysis of variance and response surface methodology. At $8000 \mathrm{rpm}$ of cutting speed and $150 \mathrm{rev} / \mathrm{min}$ of feed rate, the magnitude of Y-axes' cutting forces produces less than 10 Newton on average for PVD TiAITaN during the cutting process can be seen in Figure 7. The cutting force in Y-axes (Fy) demonstrates a higher magnitude than others due to the cutting feed of AA6061-T6 in the $Y$ direction. The negative sign in the graph represents up milling of the cutting.

Meanwhile, Figure 8 shows cutting forces in $x, y$ and $z$ axes during the machining process of AA6061-T6 for uncoated tungsten carbide at $9000 \mathrm{rpm}$ of cutting speed, $200 \mathrm{rev} / \mathrm{min}$ of feed rate, $0.5 \mathrm{~mm}$ of the depth of cut, $0.9 \mathrm{~mL} / \mathrm{min}$ of MQL flow rate and $0.09 \mathrm{wt} . \%$ of concentration. The magnitude of cutting force is demonstrated roughly 8 Newton in Y-axes, as can be seen in the graph. At $1 \mathrm{~mm}$ depth of cut, the magnitude cutting force is increased remarkably by $62 \%$ using CVD TiCN$\mathrm{Al}_{2} \mathrm{O}_{3}$ as shown in Figure 9. The higher material removal rate of AA6061-T6 in confine tolerance of the cutting tool resulting in both Fx and Fz has demonstrated a little increase of the force magnitude between 3 and 5 Newton.

Figure 10 shows a comparison of the resultant force, Fr between uncoated, CVD TiCN-Al $\mathrm{O}_{3}$ and PVD TiAITaN tungsten carbide for the machining parameters at $9000 \mathrm{rpm}$ of cutting speed, 200 $\mathrm{rev} / \mathrm{min}$ of feed rate, $1 \mathrm{~mm}$ depth of cut, $1.5 \mathrm{~mL} / \mathrm{min}$ of $\mathrm{MQL}$ flow rate and $0.09 \mathrm{w} . \%$ of concentration. There is no significant difference in cutting force regarding the cutting inserts used in the experiments except for CVD TiCN-Al ${ }_{2} \mathrm{O}_{3}$ tungsten carbide. It could probably be due to coated hardness and tool failures mechanism on both rake and flank face as the wear outs will increase the land contact area. As a result, a higher coefficient of friction exists in the tool-workpiece interface resulting in a significant increase in the cutting force components [19]. There is a correlation between cutting friction and cutting tool conditions such as chipping, wear and chips adhesion as the tool's sharpness at the initial stage of cutting produce low cutting force [11]. Thus, at the end of machining length, the frictional forces are increased remarkably when the dull cutting inserts are observed, resulting in a higher contact surface and friction coefficient. On the other hand, the cutting forces are more severely influenced by the process parameters than the physical condition of the cutting inserts. In extreme machining conditions, a higher magnitude of cutting force is required, which is a result of the proportional effect by the parameters. 


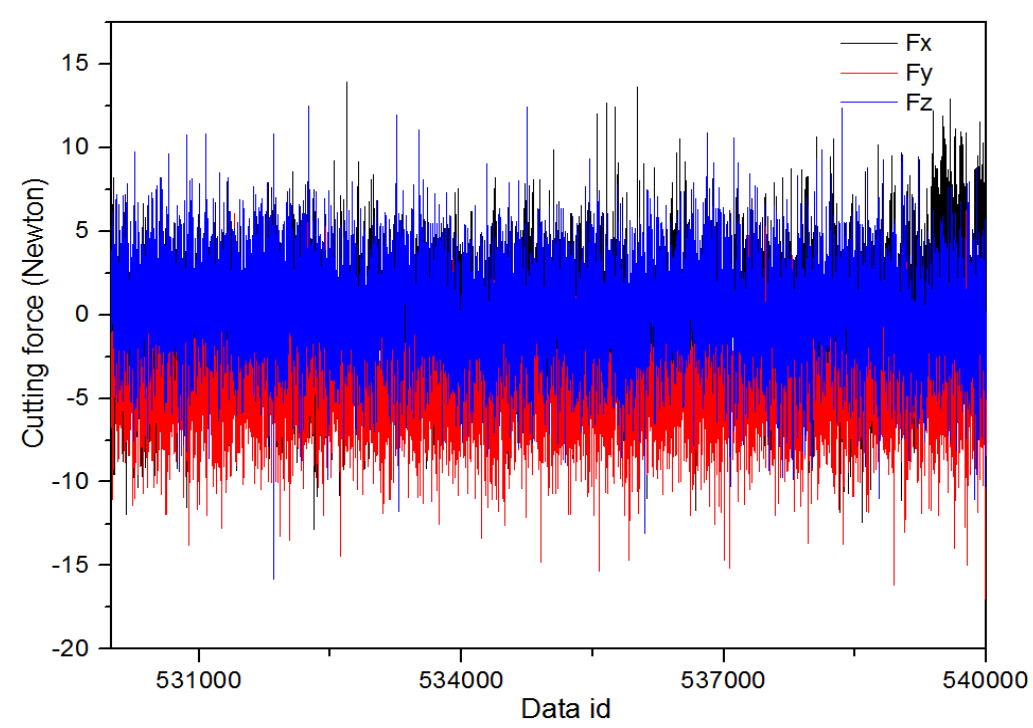

Fig. 7. Cutting forces in $x, y$ and $z$ axes during the cutting process of AA6061-T6 using PVD at cutting speed 8000rpm, feed rate $150 \mathrm{~mm} / \mathrm{min}$, depth of cut $0.75 \mathrm{~mm}$, MQL flow rate $1.2 \mathrm{~mL} / \mathrm{min}$ and concentration $0.1 \mathrm{wt} . \%$

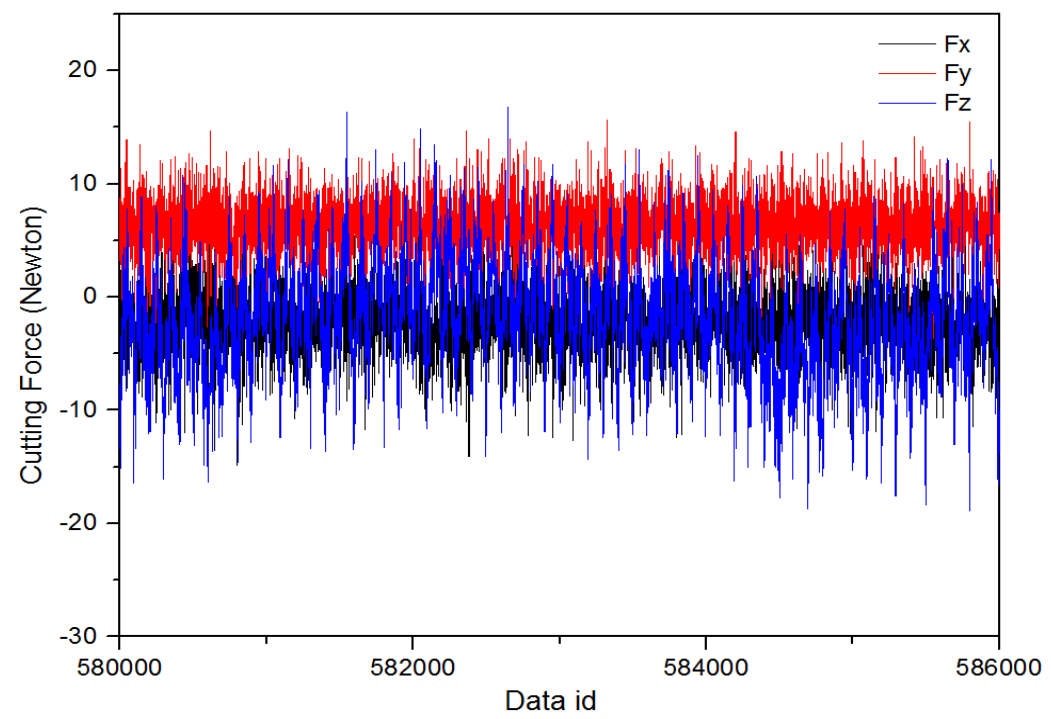

Fig. 8. Cutting forces in $x, y$ and $z$ axes during the cutting process of AA6061-T6 using uncoated tungsten carbide at cutting speed $9000 \mathrm{rpm}$, feed rate $200 \mathrm{~mm} / \mathrm{min}$, depth of cut $0.5 \mathrm{~mm}$, MQL flow rate $0.9 \mathrm{~mL} / \mathrm{min}$ and concentration $0.09 \mathrm{wt} . \%$ 


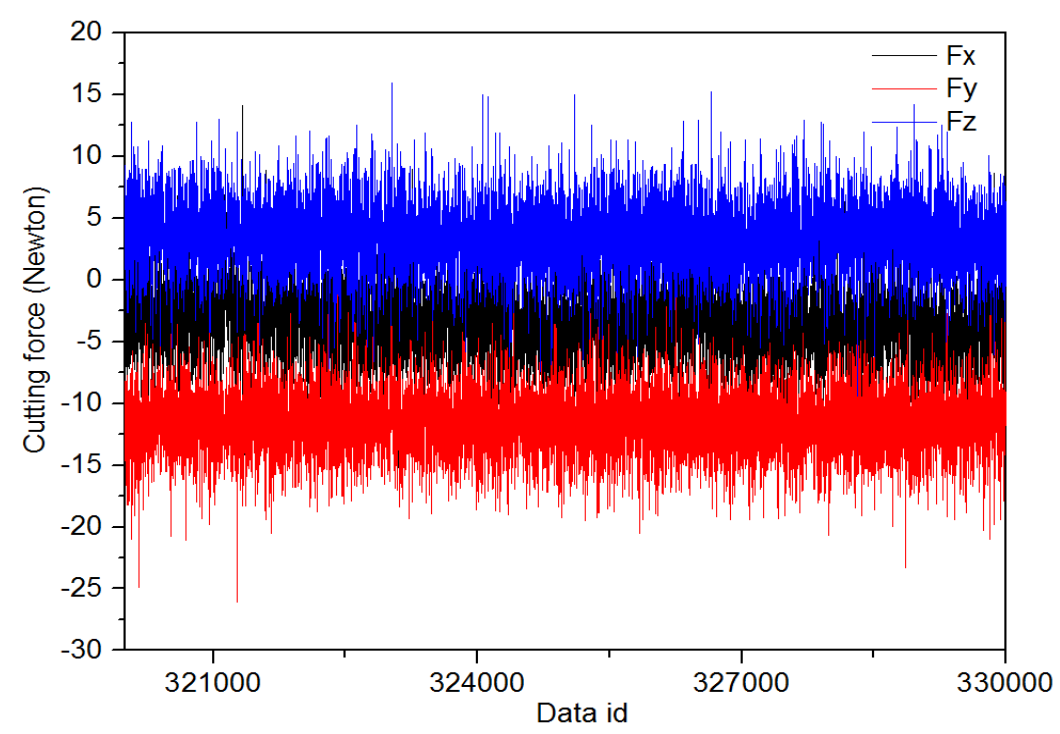

Fig. 9. Cutting forces in $x, y$ and $z$ axes during the cutting process of AA6061-T6 using CVD TiCN-Al $\mathrm{O}_{3}$ at cutting speed 9000rpm, feed rate $200 \mathrm{~mm} / \mathrm{min}$, depth of cut $1 \mathrm{~mm}$, MQL flow rate 0.9 $\mathrm{mL} / \mathrm{min}$ and concentration $0.11 \mathrm{wt} . \%$

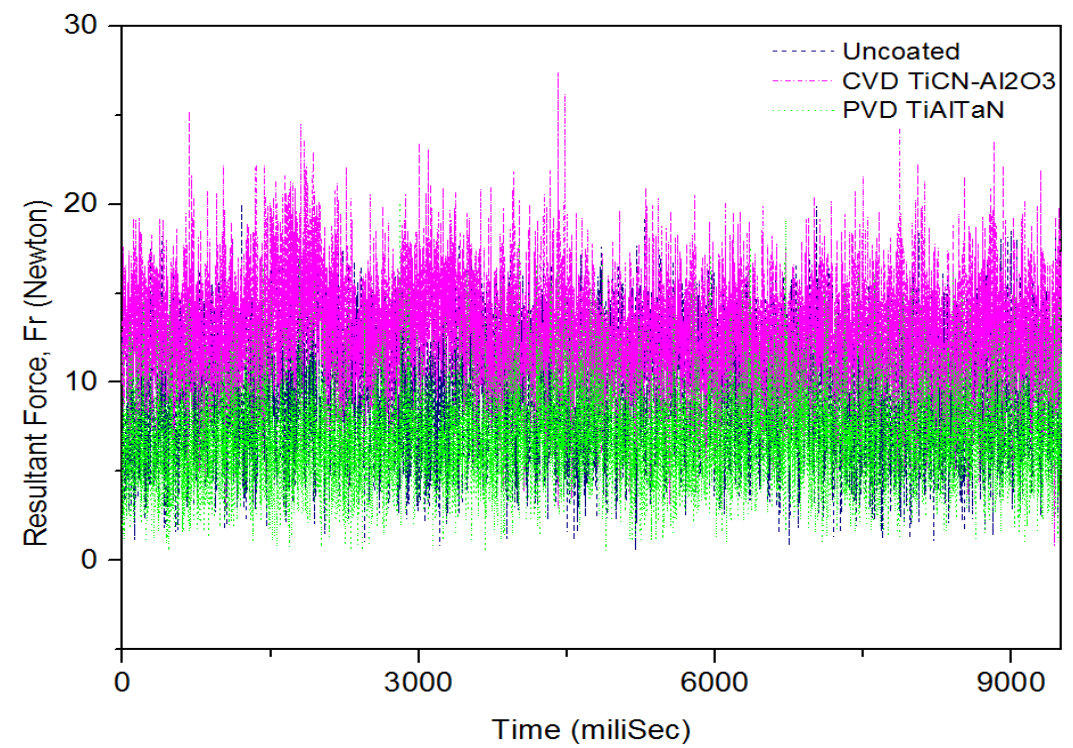

Fig. 10. Resultant force comparison between uncoated, CVD TiCN$\mathrm{Al}_{2} \mathrm{O}_{3}$ and PVD TiAITaN tungsten carbide for the same machining parameters at $9000 \mathrm{rpm}$ of cutting speed, $200 \mathrm{rev} / \mathrm{min}$ of feed rate, $1 \mathrm{~mm}$ depth of cut, $1.5 \mathrm{~mL} / \mathrm{min}$ of $\mathrm{MQL}$ flow rate and $0.09 \mathrm{w} . \%$ of concentration

The results obtained of the cutting forces magnitude are comparable to the 3D surface graphical plot in the previous section. The highest cutting force is obtained at higher cutting speed, feed rate and depth of cut. It is related to the broader chip cross-section and higher material removal rate due to a higher feed ramification, reflecting that more force is required for chip generation [20-22]. Similar findings also revealed in the literature that feeds rate was the most significant factor influencing cutting force $[3,23]$. The plastic deformation of material increase when the cutting force increased. As expected, the nanoparticle can reduce the cutting force resulting in less energy required for the plastic deformation. However, according to Cetin et al., [23], silver-nanofluids 
decreased the ability of AA7075-T6 deformation due to the heat absorption by silver nanoparticles, which led to a slight increase of cutting force by $18.55 \%$ in X-axes (Fx).

In this study, the resultant cutting force ( $\mathrm{Fr}$ ) was recorded below 30 Newton, indicating a significant improvement in the process performance. It is equivalent to $85 \%, 80 \%, 43.3 \%$ and $36.6 \%$ improvement compared to dry cutting, minimum quantity cooling lubrication (MQCL) of cryogenic and biodegradable vegetable oil of Inconel 718 [11], $1.5 \mathrm{wt} . \%$ of carbon onion nanofluids on the Duralumin AL-2017-T4 [24] and 10 wt.\% Graphite nanofluids with MQL technique of AISI 4340 steel [3].

In orthogonal cutting, the chip is being removed by the shear stress at the cutting shear plane. The contact areas between tool and chip are small, resulting in higher local stresses and pressure on the cutting tool. The chip deformation over the tool has caused localize intense shear at the rake face, also known as secondary shear. The chip thickness is associated with the lower cutting and shear angles and increases cutting shear length. Consequently, a formidable cutting force is required in the process, which may result in a rough surface, higher tool wears rate and could produce low dimensional accuracy. Therefore, the lubricant application is vital as far as enhancing the end milling process's performance was concerned.

The reduction of cutting force in removing Aluminum Alloy 6061-T6 was because of lubricating effects at the cutting interface plane when tri-hybrid nanofluids were applied to the cutting zone. As compared to other working fluids, $\mathrm{SiO}_{2}-\mathrm{Al}_{2} \mathrm{O}_{3}-\mathrm{ZrO}_{2}$ tri-hybrid nanofluids were prepared at low concentrations causing lower viscosity of the fluid in which the penetration of particles at the cutting zone is more effective in reducing the frictional forces [3]. It is associated with spherical rolling elements by tri-nanoparticles that have remarkable effects in reducing the coefficient of friction [25]. The presence of tri-nanoparticles at the cutting interface forms a thin film, which can be attributed to the lower cutting force of AA6061-T6 in the end milling process [26]. As a result, low severity of tool wear obtained at the flank using process optimization approach [27]. At higher concentrations, tri-hybrid nanofluids demonstrate higher viscosity and surface wettability, enhancing the tribology performance of metal cutting. A combination of three different nanoparticles in terms of smaller size, lower density and higher thermal capability at the cutting interface may provide tribology characteristics such as particle penetration, thin-film and ball rolling effects attributed to the lower cutting force AA6061-T6.

\section{Conclusions}

It revealed that the cutting force increased significantly at extreme machining conditions with a low concentration of nanofluids at $0.09 \mathrm{wt} . \%$. The lower cutting forces obtained can be attributed to the penetration of $\mathrm{SiO}_{2}-\mathrm{Al}_{2} \mathrm{O}_{3}-\mathrm{ZrO}_{2}$ micro-droplets at the cutting zone induced by the high pressure of the MQL system, forming a thin layer film on the tool/chip and tool/workpiece. As a result, adequate cooling and lubricating coverage received by the contact surface, decreasing the shear strength in removing AA6061-T6, subsequently reduce the friction force. It proved that based on experimental results that the cutting force, Fr measured, was between 16 Newton and 30 Newton, indicating a significant improvement in end milling process performance. Compared to the inserts, CVD TiCN-Al $\mathrm{O}_{3}$ tungsten carbide exhibited higher cutting force (Fy) due to coated hardness and tool failure mechanism on both rake and flank face. For future experimental works, combining extreme machining conditions and brittle material that affect the cutting force can be explored. 


\section{Acknowledgement}

The authors are grateful for the support given by Universiti Malaysia Pahang for providing research grants RDU1703135, PGRS 190338 and UMP LEAP-3 flagship project number RDU172203.

\section{References}

[1] S. F. Hosseini, M. Emami, and M. H. Sadeghi. "An experimental investigation on the effects of minimum quantity nano lubricant application in grinding process of Tungsten carbide." Journal of Manufacturing Processes 35, (2018): 244-253. https://doi.org/10.1016/i.jmapro.2018.08.007

[2] X. Bai, C. Li, L. Dong, and Q. Yin. "Experimental evaluation of the lubrication performances of different nanofluids for minimum quantity lubrication (MQL) in milling Ti-6Al-4V." International Journal of Advanced Manufacturing Technology 101, no. 9-12 (2019): 2621-2632. https://doi.org/10.1007/s00170-018-3100-9

[3] M. Muaz and S. K. Choudhury. "Experimental investigations and multi-objective optimization of MQL-assisted milling process for finishing of AISI 4340 steel." Measurement: Journal of the International Measurement Confederation 138 (2019): 557-569. https://doi.org/10.1016/i.measurement.2019.02.048

[4] Shao, Guodong, Deogratias Kibira, and Kevin Lyons. "A virtual machining model for sustainability analysis." In International Design Engineering Technical Conferences and Computers and Information in Engineering Conference, vol. 44113, pp. 875-883. 2010.

[5] Pervaiz, Salman, Amir Rashid, Ibrahim Deiab, and Cornel Mihai Nicolescu. "An experimental investigation on effect of minimum quantity cooling lubrication (MQCL) in machining titanium alloy (Ti6Al4V)." The International Journal of Advanced Manufacturing Technology 87, no. 5 (2016): 1371-1386. https://doi.org/10.1007/s00170-016-8969-6

[6] MacMaster, F. J., K. S. Chan, S. C. Bergsma, and M. E. Kassner. "Aluminum alloy 6069 part II: fracture toughness of 6061-T6 and 6069-T6." Materials Science and Engineering: A 289, no. 1-2 (2000): 54-59. https://doi.org/10.1016/S0921-5093(00)00918-7

[7] Chu, E., and Yu Xu. "Hydroforming of aluminum extrusion tubes for automotive applications. Part I: buckling, wrinkling and bursting analyses of aluminum tubes." International journal of mechanical sciences 46, no. 2 (2004): 263-283. https://doi.org/10.1016/i.ijmecsci.2004.02.014

[8] Abd El-Hameed, Afaf M., and Y. A. Abdel-Aziz. "Aluminium Alloys in Space Applications: A Short Report." Journal of Advanced Research in Applied Sciences and Engineering Technology 22, no. 1 (2021): 1-7. https://doi.org/10.37934/araset.22.1.17

[9] Lalwani, D. I., N. K. Mehta, and P. K. Jain. "Experimental investigations of cutting parameters influence on cutting forces and surface roughness in finish hard turning of MDN250 steel." Journal of Materials Processing Technology 206, no. 1-3 (2008): 167-179. https://doi.org/10.1016/j.jmatprotec.2007.12.018

[10] Arokiadass, R., K. Palaniradja, and N. Alagumoorthi. "Prediction and optimization of end milling process parameters of cast aluminium based MMC." Transactions of Nonferrous Metals Society of China 22, no. 7 (2012): 1568-1574. https://doi.org/10.1016/S1003-6326(11)61357-5

[11] Zhang, S., J. F. Li, and Y. W. Wang. "Tool life and cutting forces in end milling Inconel 718 under dry and minimum quantity cooling lubrication cutting conditions." Journal of Cleaner Production 32 (2012): 81-87. https://doi.org/10.1016/j.jclepro.2012.03.014

[12] Tseng, P. C., and A. Chou. "The intelligent on-line monitoring of end milling." International Journal of Machine Tools and Manufacture 42, no. 1 (2002): 89-97. https://doi.org/10.1016/S0890-6955(01)00091-8

[13] Sultan, Abdulhakim Ali, and A. Chukwujekwu Okafor. "Effects of geometric parameters of wavy-edge bull-nose helical end-mill on cutting force prediction in end-milling of Inconel 718 under MQL cooling strategy." Journal of Manufacturing Processes 23 (2016): 102-114. https://doi.org/10.1016/i.jmapro.2016.05.015

[14] Selvaraj, D. Philip. "Optimization of cutting force of duplex stainless steel in dry milling operation." Materials Today: Proceedings 4, no. 10 (2017): 11141-11147. https://doi.org/10.1016/i.matpr.2017.08.078

[15] Oganyan, Maksim, Alexey Vereschaka, Marina Volosova, and Vladimir Gurin. "Influence of the application of wearresistant coatings on force parameters of the cutting process and the tool life during end milling of titanium alloys." Materials Today: Proceedings 38 (2021): 1428-1432. https://doi.org/10.1016/i.matpr.2020.08.119

[16] Abdullah, L., Z. Jamaludin, T. H. Chiew, and N. A. Rafan. "Systematic method for cutting forces characterization for XY milling table ballscrew drive system." Int. J. Mech. Mechatron. Eng 12 (2013): 28-33. https://doi.org/10.4028/www.scientific.net/AMM.471.241

[17] Albrecht, Andreas, Simon S. Park, Yusuf Altintas, and Günter Pritschow. "High frequency bandwidth cutting force measurement in milling using capacitance displacement sensors." International Journal of Machine Tools and Manufacture 45, no. 9 (2005): 993-1008. https://doi.org/10.1016/j.ijmachtools.2004.11.028

[18] Mia, Mozammel. "Multi-response optimization of end milling parameters under through-tool cryogenic cooling condition." Measurement 111 (2017): 134-145. https://doi.org/10.1016/j.measurement.2017.07.033 
[19] Wang, Jun, C. Z. Huang, and W. G. Song. "The effect of tool flank wear on the orthogonal cutting process and its practical implications." Journal of Materials Processing Technology 142, no. 2 (2003): 338-346. https://doi.org/10.1016/S0924-0136(03)00604-6

[20] Fnides, Brahim, and M. A. Yallese. "Cutting forces and surface roughness in hard turning of hot work steel X38CrMoV5-1 using mixed ceramic." Mechanics 70, no. 2 (2008): 73-78.

[21] Kaçal, Alaattin, and Ferhat Yıldırım. "High speed hard turning of AISI S1 (60WCrV8) cold work tool steel." Acta Polytechnica Hungarica 10, no. 8 (2013): 169-186. https://doi.org/10.12700/APH.10.08.2013.8.11

[22] M. Handawi. "Performance evaluation of finish hard turning using coated carbide cutting tools under minimum quantity lubrication." PhD Thesis, Universiti Teknologi Malaysia (2016).

[23] Cetin, M. Huseyin, and Sena Kabave Kilincarslan. "Effects of cutting fluids with nano-silver and borax additives on milling performance of aluminium alloys." Journal of Manufacturing Processes 50 (2020): 170-182. https://doi.org/10.1016/i.jmapro.2019.12.042

[24] Sayuti, M., Ahmed AD Sarhan, Tomohisa Tanaka, Mohd Hamdi, and Yoshio Saito. "Cutting force reduction and surface quality improvement in machining of aerospace duralumin AL-2017-T4 using carbon onion nanolubrication system." The International Journal of Advanced Manufacturing Technology 65, no. 9-12 (2013): 1493-1500. https://doi.org/10.1007/s00170-012-4273-2

[25] Suresh Kumar Reddy, N., and Mohammed Nouari. "The influence of solid lubricant for improving tribological properties in turning process." Lubrication Science 23, no. 2 (2011): 49-59. https://doi.org/10.1002/Is.143

[26] Kadirgama, Kumaran. "Nanofluid as an Alternative Coolant in Machining: A Review." Journal of Advanced Research in Fluid Mechanics and Thermal Sciences 69, no. 1 (2020): 163-173. https://doi.org/10.37934/arfmts.69.1.163173

[27] Shah, A. H. A., A. I. Azmi, and A. N. M. Khalil. "Multi-Objective Optimization in CNC Turning of S45C Carbon Steel using Taguchi and Grey Relational Analysis Method." Journal of Advanced Research in Applied Mechanics 11, no. 1 (2015): 8-15. 